\title{
Proportion and risk factors of postnatal depression among women delivering in a government tertiary care hospital in Kerala, India
}

\author{
Naheeda Mohammed K. T. ${ }^{*}$, Lalithambica Karunakaran ${ }^{1}$, $\operatorname{Varghese~P.~Punnoose~}^{2}$
}

\begin{abstract}
${ }^{1}$ Department of Obstetrics and Gynaecology, ${ }^{2}$ Department of Psychiatry, Government T. D. Medical College,
\end{abstract} Alappuzha, Kerala, India

Received: 15 April 2021

Accepted: 05 May 2021

\section{*Correspondence:}

Dr. Naheeda Mohammed K. T.,

E-mail:nmnaheeda@gmail.com

Copyright: (c) the author(s), publisher and licensee Medip Academy. This is an open-access article distributed under the terms of the Creative Commons Attribution Non-Commercial License, which permits unrestricted non-commercial use, distribution, and reproduction in any medium, provided the original work is properly cited.

\section{ABSTRACT}

Background: The burden of postpartum depression is significant because it remains unrecognized and it not only affects the mother adversely but also has a negative consequence on the family life and the development of the infant. This research aims to aid the early diagnosis of postnatal depression using Edinburgh postnatal depression scale (EPDS) and the psychosocial and reproductive risk factors of postnatal depression among women delivering in a tertiary hospital in Kerala state, India.

Methods: 500 women were subjected to a standard questionnaire for assessing psychosocial and reproductive characteristics. The diagnosis of postnatal depression was made using a pretested and validated Malayalam version of EPDS with a score cut off of 13 or more.

Results: The proportion of postnatal depression six weeks after delivery at TD Medical College, Alappuzha was found to be $8.6 \%$. Marital harmony ( $\mathrm{p}$ value $=0.002$ ) was significantly associated with postnatal depression. Diabetes ( $\mathrm{p}$ value $=0.037)$, hypertensive disorders ( $\mathrm{p}$ value $=0.013)$, antepartum hemorrhage $(\mathrm{p}$ value $=0.036)$, neurological disorders ( $p$ value $<0.001$ ), type of delivery ( $p$ value $=0.042)$, postpartum complications ( $p$ value $=0.003$ ), mode of infant feeding ( $p$ value $=0.001)$, infant illness ( $p$ value $=0.001$ ), symptoms of maternity blues ( $p$ value $<0.0001$ ), premenstrual syndromes ( $\mathrm{p}$ value $=0.008$ ) and infertility treatment $(\mathrm{p}$ value $=0.03$ ) were significantly associated with postnatal depression.

Conclusions: Early screening of the women and counselling of women and their family will reduce the maternal morbidity and adverse child outcomes.

Keywords: Edinburgh postnatal depression scale, Postnatal depression, Postnatal mothers, Psychosocial factors, Reproductive and clinical factors

\section{INTRODUCTION}

Postpartum depression also known as postnatal depression is a non-psychotic depressive disorder of variable severity and it can begin as early as two weeks after delivery and can persist indefinitely if untreated. The illness can cause distress and impair a mother's ability to carry out her normal tasks, care for herself and care of her baby. ${ }^{1-3}$ Pregnancy and child birth can be a very rewarding and exciting time, but it can also be a period of severe emotional stress as seen in the estimated $10-25 \%$ of women suffering from postpartum depression. Much emphasis has been placed on the antenatal health than the postnatal health and more on the physical than the mental health of the mother in the developing countries. ${ }^{4,5}$ Based on the onset and the severity of postpartum mood disorders, it has been divided into three categories.

\section{Category I}

Postpartum blues also known as maternity blues which affects $40-80 \%$ of postnatal mothers. It may start as early 
as two days and last for about two weeks. Symptoms include irritability, anxiety, confusion, mood liability, sleep disturbance and crying spells. These symptoms are usually mild and they resolve with supportive care. Persistence of the maternity blues for more than two weeks may predict PPD. ${ }^{6,7}$

\section{Category II}

Postpartum depression is a non-psychotic depressive disorder that starts in or extends into postpartum period up to twelve months after delivery. It consists of any or a combination of the following symptoms: Sleeping and eating disturbance, mental confusion, loss of self-esteem, anxiety, lack of interest in one's environment, insecurity and suicidal thoughts. ${ }^{4,8-10}$

\section{Category III}

Postpartum psychosis is the severe form of the mood disorders. Mothers are severely impaired and suffer from hallucination, delusions and agitation. Generally it develops within the first four weeks after delivery. It is dangerous and often requires that the mother be hospitalized as there is increased risk of infanticide and or suicide. ${ }^{4,9}$

Meta-analysis have found psychosocial and biological risk factors associated with postnatal depression. ${ }^{11}$ Determinants of postnatal depression share themes crossculturally in resource-rich and resource-limited settings. Prenatal depression, self-esteem, childcare stress, prenatal anxiety, marital relationship, infant temperament, marital status, low social support, socioeconomic status and unplanned/unwanted pregnancy emerged as risk factors in several studies.

The symptoms of postnatal depression often lead to other manifestations such as social withdrawal, frustration, lack of enthusiasm, increased anxiety or panic attacks and decreased sex drive that ultimately affects the quality of life of the patient resulting in strained bonding with the new born and future marital relationships. ${ }^{11}$ Although the risk of self-harm is low in postnatal depression, assessment of it is essential and in case of detection of suicidal or infanticidal ideation, psychiatric referral becomes mandatory. ${ }^{12}$ Antenatal depression has been documented to be significantly associated with postnatal depression. Independently it has been shown to be a significant predictor of postnatal depression. South Asian communities have consistently shown that the preference for male children is deeply rooted in the socio-cultural milieu. Women are often blamed for the birth of girls, especially if it's the second girl child. ${ }^{13}$

In India, the incidence of postnatal depression has been reported to be $11-23 \%$ with depression persisting in even after 6 months of childbirth in around $11-14 \%$ of women. ${ }^{13,14}$ While risk factors for this condition such as poor marital relationship, antenatal depression as reported in western countries is also replicated in the Indian population, specific cultural and social factors modify risk for the disorder in India. ${ }^{13,14}$ Disappointment with the birth of a girl child, poverty, intimate partner violence and having a second girl child are risk factors for postnatal depression and its chronicity in the Indian context. ${ }^{15}$ The occurrence and chronicity as documented is the cause of significantly higher levels of morbidity among the majority of the affected women who remained ill even after six months. ${ }^{16}$ This can lead to adverse health outcomes, particularly for women and also their children. These women have responsibility of caring for their children while being in poor mental health state. This could lead to adverse consequences for the child's health and development. Studies from India and Pakistan document the adverse effect of postnatal depression on infant's failure to thrive. ${ }^{13}$ An infant's failure to thrive has a damaging effect on its overall growth and development. Effective, affordable community based intervention studies from resource poor settings like India are scarce.

This research aims to aid the early diagnosis of postnatal depression and the psychosocial and reproductive characteristics and psychiatric determinants of depression among postnatal women in a tertiary hospital in Kerala state, India.

\section{METHODS}

A cross sectional study was performed among women delivered in the Department of Obstetrics and Gynaecology of a tertiary care hospital in Kerala, India, for a duration of 1 year. Postnatal patients from the postnatal ward of department of Obstetrics and Gynaecology, T. D. Medical College, Alappuzha, who agreed to participate in the study were enrolled consecutively into the study till the sample size of 500 was attained. Postnatal patients who have not given consent for this study and those who were known cases of mental illness were excluded.

After explaining the nature and purpose of study, an informed consent was taken from the participants and from a relative. During their hospital stay, a direct interview for psychosocial and reproductive characteristics was conducted to assess the risk factors. These patients were reviewed in the family planning OPD, when they come for postnatal checkup, after 6 weeks of delivery. Those who developed depressive symptoms before 6 weeks, were asked to come in between. During their follow up visit, a pretested and validated Malayalam version of EPDS was used to detect depressive symptoms in them. EPDS scale has 10 components in it. Each item is rated from 0 to 3 , yielding a total score of 0 to 30 . Seven of its items are reverse scored. An EPDS score cut off 13 on Malayalam version of EPDS was used to calculate the proportion of postnatal depression in the present study.

The data obtained from the patient was entered into Microsoft excel sheet and analyzed using statistical package for the social sciences (SPSS) software. Data 
analysis was done using percentages and proportions. Frequencies were generated, variables compared and test of significance carried out using chi square for categorized variables. A p value $<0.05$ was considered statistically significant.

Permission to conduct the study was obtained from institutional research committee and institutional ethical committee of Govt. T.D. Medical College Hospital, Alappuzha. Participation to this study was voluntary. Confidentiality was maintained for all obtained information. There was no risk to the participants as there were no drugs given, no procedures performed and no specimens taken.

Declining to participate into the study did not affect the services rendered by the health service providers and advice was given on importance of postpartum mental health in general. Those identified with postnatal depression was counseled and guided to avail proper treatment.

\section{RESULTS}

Of the 500 participants, 43 mothers $(8.6 \%)$ were found to have postpartum depressive symptoms as measured by an EPDS score of $\geq 13$. It is also important to note that 3 mothers $(0.6 \%)$ answered positively in the EPDS question about suicidal ideation. The question asked "the thought of harming myself has occurred to me", these 3 mothers answered "sometimes".

\section{Psychosocial characteristics}

The association of the psychosocial variables with postpartum depression was tested. The mothers with PND were higher in those aged $>21$ years $(9.2 \%)$, than those aged $\leq 21$ years $(5.1 \%)$. But this was not found to be statistically significant. The mothers with PND were more in Christian religion (12.3\%), than that of Hindus $(8.5 \%)$ and Muslims (6.3\%); but this was not found to be statistically significant. Mothers with education below $10^{\text {th }}$ standard were more affected with depressive symptoms $(13.8 \%)$ when compared to their counterparts (7.5\%).

PND was very significantly higher in unmarried (100\%) than in those who are married (8.4\%). This marital status has got a statistically significant association with PND with a $p$ value of 0.001 . Similarly, the marital harmony has got statistically significant association with PND; with $19.6 \%$ of PND in those who have non harmonious relationship with their partners, when compared to those with harmonious relationship $(7.1 \%)$. There was no significant difference based on spousal alcoholism $(8.3 \%$ in alcoholics and $8.5 \%$ in non-alcoholics). Mothers who lived in a joint/extended family had a lower number of PND (7\%), than those lived in nuclear families (10.1\%).

PND was more in unemployed mothers (10.6\%) than employed (8.2\%); but this was not found to be statistically significant. Regarding partner's occupation, unemployed were more affected with depressive symptoms (14.3\%) than those who were employed $(8.2 \%)$. PND was more in those with an annual income of $>40,000(11 \%)$, than those with income $\leq 40,000(8.1 \%)$. These variables were not found to be statistically significant. PND among those belonging to a BPL family was $8.8 \%$ and among those belonging to APL family was $7.9 \%$. But this difference was not found to be statistically significant. Analysis revealed significant association ( $\mathrm{p}$ value <0.05) of psychosocial factors (marital status, marital harmony) with PND. Marital status with $\mathrm{p}$ value $=0.001$ and marital harmony with $\mathrm{p}$ value $=0.002$.

\section{Reproductive and clinical characteristics}

The association of the reproductive and clinical variables with postpartum depression was tested. There was no significant association between PND and gravidity, parity, number of living children, pregnancy desire. Though PND was found to be more among multigravidas and those with undesired pregnancy, but, this was not found to be statistically significant.

Regarding the complications in pregnancy, PND was higher in diabetic mothers (13.2\%) than non- diabetic $(7.1 \%)$; with a $\mathrm{p}$ value of 0.037 . PND was more in hypertensive mothers $(17.2 \%)$ than non-hypertensives $(7.5 \%)$; with a $p$ value of 0.013 . Antepartum hemorrhage has got a statistically significant association with PND with a $\mathrm{p}$ value of 0.036 . PND was higher in those with neurological diseases $(35.7 \%)$ than without neurological disease $(7.8 \%)$; with a $p$ value of $<0.001$. Association of PND with anemia, thyroid disorders, threatened abortion, heart diseases and respiratory diseases were studied, but no significant association was found.

In terms of birth related variables, gestational age at delivery has got a statistically significant association with PND ( $\mathrm{p}$ value $=0.042$ ), with PND higher among those delivered preterm $(14.3 \%)$ than among those delivered full term (7.5\%). Postpartum complications has got a statistically significant association with PND (p value=0.003), with PND higher among those with complications $(23.3 \%)$ than among those without $(7.7 \%)$. PND was higher in those mothers who fed their babies with formula feeds $(18.5 \%)$ than those who exclusively breast fed their babies $(6.7 \%)$; with a $\mathrm{p}$ value $=0.001$. Infant illness has got a statistically significant association with PND ( $p$ value $=0.001$ ), with PND higher among those mothers, whose babies required NICU admission (15.8\%) than among those without NICU admission (6.3\%).

Mode of delivery was not significantly associated with PND ( $\mathrm{p}$ value $=0.687$ ). PND was higher in those undergone instrumental delivery (25\%) than those without $(8.3 \%)$; and this has no statistically significant association with PND. PND was more among those delivered by emergency caesarean delivery $(10.1 \%)$ than those by elective section (5.4\%). Sex of infant was not significantly 
associated with PND (p value=0.0.857); with PND almost similar among those with female babies $(8.8 \%)$ and male babies $(8.4 \%)$. PND was higher in those who had their babies with congenital anomalies $(25 \%)$ than those without (6.3\%); with no statistically significant association.
Symptoms of maternity blues ( $\mathrm{p}$ value <0.0001), premenstrual syndrome (0.008) and infertility treatment $(0.03 \%)$ had significant association with PND. The association of PND with pregnancy loss, IUD, stillbirth and mental illness in family were studied, but no significant association was found.

Table 1: Analysis of psychosocial characteristics and postnatal depression.

\begin{tabular}{|c|c|c|c|c|}
\hline Variable & No. (\%) depressed & No. (\%) not depressed & Chi-square & $P$ value \\
\hline \multicolumn{5}{|l|}{ Age } \\
\hline$\leq 21$ & $4(5.1)$ & $74(94.9)$ & \multirow{2}{*}{1.417} & \multirow{2}{*}{0.234} \\
\hline$>21$ & $39(9.2)$ & $383(90.8)$ & & \\
\hline \multicolumn{5}{|l|}{ Religion } \\
\hline Hindu & $30(8.5)$ & $317(91.4)$ & \multirow{3}{*}{1.658} & \multirow{3}{*}{0.437} \\
\hline Muslim & $6(6.3)$ & $90(93.8)$ & & \\
\hline Christian & $7(12.3)$ & $50(87.7)$ & & \\
\hline \multicolumn{5}{|l|}{ Education } \\
\hline Below 10th & $12(13.8)$ & $75(86.2)$ & \multirow[t]{2}{*}{3.614} & \multirow[t]{2}{*}{0.057} \\
\hline Above 10th & $31(7.5)$ & $382(92.5)$ & & \\
\hline \multicolumn{5}{|l|}{ Marital status } \\
\hline Unmarried & $1(100)$ & $0(0)$ & \multirow{2}{*}{10.649} & \multirow{2}{*}{$0.001 * *$} \\
\hline Married & $42(8.4)$ & 457 (91.6) & & \\
\hline \multicolumn{5}{|c|}{ Marital harmony } \\
\hline Harmonious & $32(7.1)$ & $416(92.9)$ & \multirow{2}{*}{9.229} & \multirow{2}{*}{$0.002 * *$} \\
\hline Not harmonious & $10(19.6)$ & $41(80.4)$ & & \\
\hline \multicolumn{5}{|c|}{ Alcoholism in partner } \\
\hline Yes & $13(8.3)$ & $144(91.7)$ & \multirow{2}{*}{0.006} & \multirow{2}{*}{0.941} \\
\hline No & $29(8.5)$ & $313(91.5)$ & & \\
\hline \multicolumn{5}{|l|}{ Type of family } \\
\hline Joint & $19(7)$ & $252(93)$ & \multirow{2}{*}{1.521} & \multirow{2}{*}{0.218} \\
\hline Nuclear & $23(10.1)$ & $205(89.9)$ & & \\
\hline \multicolumn{5}{|l|}{ Occupation } \\
\hline Unemployed & $34(8.2)$ & $381(91.8)$ & \multirow{2}{*}{0.515} & \multirow{2}{*}{0.473} \\
\hline Employed & $9(10.6)$ & $76(89.4)$ & & \\
\hline \multicolumn{5}{|c|}{ Partner's occupation } \\
\hline Employed & $39(8.2)$ & $439(91.8)$ & \multirow{2}{*}{0.980} & \multirow{2}{*}{0.322} \\
\hline Unemployed & $3(14.3)$ & $18(85.7)$ & & \\
\hline \multicolumn{5}{|l|}{ Annual income } \\
\hline$\leq 40000$ & $33(8.1)$ & $376(91.9)$ & \multirow{2}{*}{0.808} & \\
\hline$>40000$ & $10(11)$ & $81(89)$ & & 0.369 \\
\hline Economic status & & & & \\
\hline APL & $9(7.9)$ & $105(92.1)$ & & \\
\hline BPL & $34(8.8)$ & $352(91.2)$ & 0.093 & 0.760 \\
\hline
\end{tabular}

**statistically significant association between the variable and postnatal depression

Table 2: Analysis of reproductive and clinical characteristics and postnatal depression.

\begin{tabular}{|c|c|c|c|c|}
\hline Variable & No. (\%) depressed & No. (\%) not depressed & Chi-square & P value \\
\hline \multicolumn{5}{|l|}{ Gravidity } \\
\hline 1 & $18(7.3)$ & $228(92.7)$ & \multirow{3}{*}{1.614} & \multirow{3}{*}{0.446} \\
\hline 2 & $15(8.9)$ & $154(91.1)$ & & \\
\hline$\geq 3$ & $10(11.8)$ & $75(88.2)$ & & \\
\hline \multicolumn{5}{|l|}{ Parity } \\
\hline 0 & $21(7.1)$ & $251(92.3)$ & \multirow{3}{*}{0.808} & \multirow{3}{*}{0.667} \\
\hline 1 & $18(10.1)$ & $160(89.9)$ & & \\
\hline$\geq 2$ & $4(8)$ & $46(92)$ & & \\
\hline \multicolumn{5}{|c|}{ Living children } \\
\hline 0 & $20(7.4)$ & $250(92.6)$ & 2.253 & 0.324 \\
\hline
\end{tabular}




\begin{tabular}{|c|c|c|c|c|}
\hline Variable & No. $(\%)$ depressed & No. (\%) not depressed & Chi-square & P value \\
\hline$\leq 3$ & $20(11)$ & $161(89)$ & & \\
\hline$>3$ & $3(6.1)$ & $46(93.9)$ & & \\
\hline \multicolumn{5}{|l|}{ Pregnancy } \\
\hline Desired & $36(8.3)$ & $398(91.7)$ & \multirow{2}{*}{0.389} & \multirow{2}{*}{0.533} \\
\hline Undesired & $7(10.6)$ & $59(89.4)$ & & \\
\hline \multicolumn{5}{|l|}{ Diabetes } \\
\hline Yes & $16(13.2)$ & $105(86.8)$ & \multirow{2}{*}{4.341} & \multirow{2}{*}{$0.037 * *$} \\
\hline No & $27(7.1)$ & $352(92.9)$ & & \\
\hline \multicolumn{5}{|c|}{ Hypertensive disorders } \\
\hline Yes & $10(17.2)$ & $48(82.8)$ & \multirow{2}{*}{6.233} & \multirow{2}{*}{$0.013 * *$} \\
\hline No & $33(7.5)$ & $409(92.5)$ & & \\
\hline \multicolumn{5}{|c|}{ Antepartum hemorrhage } \\
\hline Yes & $1(50)$ & $1(50)$ & \multirow{2}{*}{4.379} & \multirow{2}{*}{$0.036 * *$} \\
\hline No & $42(8.4)$ & $456(91.6)$ & & \\
\hline \multicolumn{5}{|l|}{ Anemia } \\
\hline Yes & $2(7.1)$ & $26(92.9)$ & \multirow{2}{*}{0.08} & \multirow{2}{*}{0.77} \\
\hline No & $41(8.7)$ & $431(91.3)$ & & \\
\hline \multicolumn{5}{|c|}{ Thyroid disorders } \\
\hline Yes & $5(12.5)$ & $36(87.8)$ & \multirow{2}{*}{0.734} & \multirow{2}{*}{0.391} \\
\hline No & $38(8.3)$ & $421(91.7)$ & & \\
\hline Threatened abor & & & & \\
\hline Yes & $1(12.5)$ & $7(87.5)$ & & \\
\hline No & $42(8.5)$ & $450(91.5)$ & 0.157 & 0.692 \\
\hline Heart diseases & & & & \\
\hline Yes & $1(16.7)$ & $5(83.3)$ & & \\
\hline No & $42(8.5)$ & $452(91.5)$ & 0.503 & 0.478 \\
\hline Respiratory dise & & & & \\
\hline Yes & $1(11.1)$ & $8(88.9)$ & & \\
\hline No & $42(8.6)$ & $449(91.4)$ & 0.074 & 0.786 \\
\hline Neurological dis & & & & \\
\hline Yes & $5(35.7)$ & $9(64.3)$ & & \\
\hline No & $38(7.8)$ & $448(92.2)$ & 13.471 & $<0.001 \%$ \\
\hline Mode of delivery & & & & \\
\hline Vaginal & $25(8.2)$ & $280(91.8)$ & & \\
\hline $\mathrm{CS}$ & $18(9.2)$ & $177(90.8)$ & 0.162 & 0.687 \\
\hline Instrumental & & & & \\
\hline Yes & $2(25)$ & $6(75)$ & & \\
\hline No & $41(8.3)$ & $451(91.7)$ & 2.782 & 0.095 \\
\hline Type of CS & & & & \\
\hline Emergency & $16(10.1)$ & $142(89.9)$ & & \\
\hline Elective & $2(5.4)$ & $35(94.6)$ & 0.798 & 0.372 \\
\hline Type of delivery & & & & \\
\hline Full term & $31(7.5)$ & $385(92.5)$ & & $0042 * *$ \\
\hline preterm & $12(14.3)$ & $72(85.7)$ & 4.152 & $0.042^{* *}$ \\
\hline Postpartum com & & & & \\
\hline Yes & $7(23.3)$ & $23(76.7)$ & 8814 & $0002 * *$ \\
\hline No & $36(7.7)$ & $434(92.3)$ & 8.814 & 0.003 \\
\hline Sex of infant & & & & \\
\hline Male & $23(8.4)$ & $251(91.6)$ & & \\
\hline Female & $20(8.8)$ & $206(91.2)$ & 0.033 & 0.857 \\
\hline Mode of infant $f$ & & & & \\
\hline $\mathrm{EBF}$ & $28(6.7)$ & $391(93.3)$ & & \\
\hline Formula feeding & $15(18.5)$ & $66(81.5)$ & 12.097 & $0.001 * *$ \\
\hline Infant illness & & & & \\
\hline NICU & $19(15.8)$ & $101(84.2)$ & & \\
\hline None & $24(6.3)$ & $356(93.7)$ & 10.510 & $0.001^{* *}$ \\
\hline
\end{tabular}

Continued. 


\begin{tabular}{|c|c|c|c|c|}
\hline Variable & No. (\%) depressed & No. (\%) not depressed & Chi-square & $P$ value \\
\hline Yes & $2(25)$ & $6(75)$ & \multirow{2}{*}{2.782} & \multirow{2}{*}{0.095} \\
\hline No & $41(8.3)$ & $451(91.7)$ & & \\
\hline \multicolumn{5}{|c|}{ Symptoms of maternity blues } \\
\hline Present & $5(62.5)$ & $3(37.5)$ & \multirow{2}{*}{30.049} & \multirow{2}{*}{$<0.0001 * *$} \\
\hline Absent & $38(7.7)$ & $454(92.3)$ & & \\
\hline \multicolumn{5}{|c|}{ Premenstrual syndrome } \\
\hline Yes & $3(33.3)$ & $6(66.7)$ & \multirow{2}{*}{7.133} & \multirow{2}{*}{$0.008 * *$} \\
\hline No & $40(8.1)$ & $451(91.9)$ & & \\
\hline \multicolumn{5}{|c|}{ Infertility treatment } \\
\hline Yes & $2(33.3)$ & $4(66.7)$ & \multirow{2}{*}{4.726} & \multirow{2}{*}{$0.03 * *$} \\
\hline No & $41(8.3)$ & $453(91.7)$ & & \\
\hline \multicolumn{5}{|c|}{ Pregnancy loss } \\
\hline Yes & $7(12.7)$ & $48(87.3)$ & \multirow{2}{*}{1.339} & \multirow{2}{*}{0.247} \\
\hline No & $36(8.1)$ & $409(91.9)$ & & \\
\hline \multicolumn{5}{|l|}{ IUD } \\
\hline Yes & $1(33.3)$ & $2(66.7)$ & \multirow{2}{*}{2.349} & \multirow{2}{*}{0.125} \\
\hline No & $42(8.5)$ & $455(91.5)$ & & \\
\hline \multicolumn{5}{|l|}{ Stillbirth } \\
\hline Yes & $0(0)$ & $1(100)$ & \multirow{2}{*}{0.094} & \multirow{2}{*}{0.759} \\
\hline No & $43(8.6)$ & $456(91.4)$ & & \\
\hline \multicolumn{5}{|c|}{ Mental illness in family } \\
\hline Yes & $0(0)$ & $1(100)$ & \multirow{2}{*}{0.094} & \multirow{2}{*}{0.759} \\
\hline No & $43(8.6)$ & $456(91.4)$ & & \\
\hline
\end{tabular}

**statistically significant association between the variable and postnatal depression

\section{DISCUSSION}

Based on Shorey et al systematic review and meta-analysis of 58 studies (1988-2016) on the prevalence of postnatal depression, prevalence rate of postnatal depression is $17 \%$. This study found the proportion of PND to be $8.6 \%$ at six weeks postpartum. The prevalence of PND ranges from $7.6 \%$ to $39 \%$ in various areas of the world and differs according to the population tested and screening tools used. Study done in Goa, Mangalore and Delhi showed the prevalence $22 \%, 31.44 \%$ and $24 \%$ respectively.

The fact that the literature demonstrates a wide variations in what is considered as a significant score on the EPDS, may be the prevalence would have been higher had the significant score been lowered to 11 or 12 as described in the development of the EPDS. Further the prevalence obtained in this study could be an underestimate since some mothers may not have attended postnatal clinic especially if they felt like they were physically well, if they are uneducated or of low socio economic status. All women are susceptible to developing depression following childbirth.

The mothers with PND were higher in those aged $>21$ years $(9.2 \%)$, than those aged $\leq 21$ years $(5.1 \%)$. Previous studies have yielded mixed findings in relation to age as a risk factor. ${ }^{17}$ Mothers with education below $10^{\text {th }}$ standard were more affected with depressive symptoms (13.8\%) when compared to their counterparts $(7.5 \%)$. One study found that those who were depressed during pregnancy were less well-educated. ${ }^{18}$
The sample size of unmarried mothers is small in this study with only 1 unmarried mother. Hence, the impact of marital status on PND cannot be ascertained. Single marital status was associated in several studies with PND, in Finland only with recurrent depression. ${ }^{11,19,20}$ The marital harmony has got statistically significant association with PND. PND is higher in those who have non harmonious relationship with their partners, which corroborates several previous studies. ${ }^{11,17,21}$ There was no significant difference based on spousal alcoholism. Mothers who lived in a joint/extended family had a lower number of PND, than those lived in nuclear families.

PND was more in unemployed mothers than employed. Regarding partner's occupation, unemployed were more affected with depressive symptoms than those who were employed. PND was more in those with an annual income of $>40,000$, than those with income $\leq 40,000$. Depressed mothers seem to have fewer socioeconomic resources to cope with the transition to motherhood. They had poor economic situation and poor housing condition more often, and they had less basic education, and commonly lacked professional education more frequently than did nondepressed mothers.

PND was found to be more among multigravidas than among primi. PND was higher in those with undesired pregnancy. Several studies show significant association of undesired pregnancy to PND. ${ }^{11,17,22}$ PND was higher in diabetic and hypertensive mothers than non- diabetic and non hypertensives, respectively. PND has statistically significant association with antepartum haemorrhage and neurological diseases. PND was higher in those with 
thyroid disorders, threatened abortion, respiratory disease and heart disease, but, without statistical significance. Pregnancy-related complications are generally potential risk factors for PND. ${ }^{17,20,23}$

PND was higher among those delivered preterm. PND was higher in those undergone instrumental delivery and those delivered by emergency cesarean delivery .But, several earlier studies show cesarean section (elective or emergency) was equally common among depressed and non-depressed mothers. ${ }^{17,22}$ PND was higher among those with postpartum complications than among those without.

Gender of the baby had no role in determining postnatal depression similar to studies conducted within Western societies where there was no association between the sex of the child and postpartum depression while it is in striking contrast with several Indian studies where mothers who gave birth to a female child had an increased odds of developing PND.

PND was higher in those mothers who fed their babies with formula feeds than those who exclusively breast fed their babies; like many earlier studies, which showed that depressed mothers more commonly did not breastfeed. ${ }^{17,24-}$ ${ }^{26}$ This may be because breastfeeding may protect against depression or assist in a speedier recovery from symptoms or conversely, PND may reduce the rates of breastfeeding. ${ }^{24-26}$

PND was higher in those who had their babies with congenital anomalies and whose babies required NICU admission; like previous studies. ${ }^{17,20,27}$ Worries about infant's health are suggested to be a powerful predictor of postnatal depressive symptoms. ${ }^{28}$

PND was more among those with symptoms of maternity blues and premenstrual syndrome. It is important to consider that in this study, the sample size of infertility treated is small, may be due to the lack of availability of assisted reproductive techniques in our hospital. In this study, only 6 patients had undergone infertility treatment. Those who had undergone infertility treatment had higher PND. PND was more in those with history of pregnancy loss, IUD. Some previous studies have reported a connection between prior pregnancy losses and PND. ${ }^{20,29}$ In this study, the sample of mothers with family history of mental illness is small, probably because the patient may not have revealed the accurate information. Hence, the association between family history of mental illness and PND cannot be ascertained in this study. But, a family history of depression was significantly associated with PND in a study in Delhi, Bangalore Johnstone et al. ${ }^{30}$

The study findings illustrated that the psychosocial variables (marital harmony), and reproductive and clinical variables (diabetes, hypertensive disorders, antepartum haemorrhage, neurological disease, gestational age at delivery, postpartum complications, mode of infant feeding, infant illness, symptoms of maternity blues, premenstrual syndrome, infertility treatment) were having a statistically significant association with PND.

\section{CONCLUSION}

According to this study, proportion of PND among women at 6 weeks postpartum is $8.6 \%$, which is a significant value and compared well with other studies. Assessment and management of postpartum depression is not an integral part of maternal and child health care programmes in India at present. In fact this has not yet been recognised as a valid public health problem in the country as evidenced by the scarce research activity on the subject in the country. The variables used in this study can be easily recognized and therefore can be used for screening; so that, this would help prevent PND at all levels hence a healthy mother.

\section{ACKNOWLEDGMENTS}

Authors would like to thank Department of Obstetrics and Gynaecology and Department of Psychiatry, T.D. Medical College, Alappey for their support during study.

\section{Funding: No funding sources}

Conflict of interest: None declared

Ethical approval: The study was approved by the Institutional Ethics Committee

\section{REFERENCES}

1. Ministry of health to formulate policies integrating mental and reproductive health. New Pathways New Hope. 2014.

2. Hatton DC, Harrison-Hohner J, Coste S, Dorato V, Curet LB, McCarron DA. Symptoms of postpartum depression and breastfeeding. J Hum Lact. 2005;21(4):444-9.

3. Lanes A, Jennifer LK, Hala T. Prevalence and characteristics of postpartum symptomatology among Canadian women. BMC Public Health. 2011;11:302.

4. American Psychiatric Association. Diagnostic and statistical manual of mental disorders. 4th Ed, text rev. Washington, DC: American Psychiatric Association. 2002.

5. Evins GG, Theophrastus JP, Galvin SL. Postpartum depression: A comparison of screening and routine clinical evaluation. Am J Obstet Gynecol. 2000;182:1080-2.

6. Dennis CE, Stewart DE. Treatment of postpartum depression, Part 1: A critical review of biological interventions. J Clin Psychiatr. 2004;45:1242-51.

7. LaMonde LG. Feeling blue or is it something more? A review of postpartum depression. Super twins. 2006;16(4):53-4.

8. Bennett HA, Einarson A, Taddio A, Koren G, Einarson TR. Prevalence of depression during pregnancy: systematic review. Obstet Gynecol. 2004;103(4):698-709.

9. Evans J, Heron J, Patel RR, Wiles N. Depressive symptoms during pregnancy and low birth weight at 
term: longitudinal study. $\mathrm{Br} \mathrm{J}$ Psychiatry. 2007;191:84-5.

10. National Institute for Health and Clinical Excellence. Antenatal and postnatal mental health; Clinical management and service guidance (Brief record). London: NICE. 2007.

11. Beck CT. Predictors of postpartum depression. An Update. Nursing Res. 2001;50:275-85.

12. Alici-Evcimen Y, Sudak DM. Postpartum Depression. Psy Update. 2003;10:2106.

13. Patel V, Rahman A, Jacob KS, Hughes M. Effect of maternal mental health on infant growth in low income countries: New evidence from South Asia. BMJ. 2004;328:820-3.

14. Chandran M, Tharyan P, Muliyil J, Abraham S. Postpartum depression in a cohort of women from a rural area of Tamil Nadu, India. Incidence and risk factors. Br J Psychiatry. 2002;181:499-504.

15. Chandra PS. Post-partum psychiatric care in India: The need for integration and innovation. World Psychiatry. 2004;3:99-100.

16. Patel V, Rodrigues M, DeSouza N. Gender, Poverty, and Postnatal Depression: A Study of Mothers in Goa, India. Am J Psychiatry. 2002;159:43-7.

17. Norhayati MN, Nik Hazlina NH, Asrenee AR, Wan Emilin WMA. Magnitude and risk factors for postpartum symptoms: A literature review. J Affect Disord. 2015;175:4-52.

18. Gotlib IH, Whiffen VE, Mount JH, Milne K, Cordy NI. Prevalence rates and demographic characteristics associated with depression in pregnancy and the postpartum. J Consult Clin Psychol. 1989;57(2):26974.

19. Halbreih U. Postpartum disorders: Multiple interacting underlying mechanism and risk factors. J Affect Disord. 2005;88(1):1-7.

20. Räisänen S, Lehto SM, Nielsen HS, Gissler M, Kramer MR, Heinonen S. Fear of childbirth predicts postpartum depression: a population-based analysis of 511422 singleton births in Finland. BMJ Open. 2013;3(11):e004047.

21. Ross LE, Dennis CL. The prevalence of postpartum depression among women with substance use, an abuse history, or chronic illness: a systematic review. J Womens Health. 2009;18(4):475-86.

22. Robertson E, Grace S, Wallington T, Stewart DE. 2004. Antenatal risk factors for postpartum depression: a synthesis of recent literature. Gen Hosp Psychiatry. 2004;26(4):289-95.

23. Ruohomäki A, Toffol E, Upadhyaya S, Keski-Nisula L, Pekkanen J, Lampi J, et al. The association between gestational diabetes mellitus and postpartum depressive symptomatology: A prospective cohort study. J Affect Disord. 2018;241:263-8.

24. Warner R, Appleby L, Whitton A, Faragher B. Demographic and obstetric risk factors for postnatal psychiatric morbidity. $\mathrm{Br}$ J Psychiatry. 1996;168(5):607-11.

25. Hamdan A, Tamim H. The relationship between postpartum depression and breastfeeding. Int $\mathbf{J}$ Psychiatry Med. 2012;43(3):243-59.

26. Figueiredo B, Dias CC, Brandão S, Canário C, NunesCosta R. Breastfeeding and postpartum depression: state of the art review. J Pediatr (Rio J). 2013;89(4):332-8.

27. Britton JR. Infant temperament and maternal anxiety and depressed mood in the early postpartum period. Women Health. 2011;51(1):55-71.

28. Thome M. Predictors of postpartum depressive symptoms in Icelandic women. Arch Womens Ment Health. 2000;3(1):7-14.

29. Giannandrea SAM, Cerulli C, Anson E, Chaudron LH. Increased risk for postpartum psychiatric disorders among women with past pregnancy loss. J Womens Health (Larchmt). 2013;22(9):760-8.

30. Johnstone SJ, Boyce PM, Hickey AR, Yatees AD, Harris MG. Obstetric risk factors for postnatal depression in urban and rural community samples. Australian New Zealand J Psych. 2001;35:69-74.

Cite this article as: Naheeda MKT, Karunakaran L, Punnoose VP. Proportion and risk factors of postnatal depression among women delivering in a government tertiary care hospital in Kerala, India. Int J Reprod Contracept Obstet Gynecol 2021;10:2395-402. 